\title{
BMJ Open Involving migrants in the development of guidelines for communication in cross-cultural general practice consultations: a participatory learning and action research project
}

Mary O’Reilly-de Brún, ${ }^{1}$ Anne MacFarlane ${ }^{2}$ Tomas de Brún, ${ }^{1}$ Ekaterina Okonkwo, ${ }^{1,3}$ Jean Samuel Bonsenge Bokanga, ${ }^{1}$ Maria Manuela De Almeida Silva, ${ }^{1,4}$

Florence Ogbebor, ${ }^{1}$ Aga Mierzejewska, ${ }^{1}$ Lovina Nnadi, ${ }^{1}$ Maria van den Muijsenbergh, ${ }^{5}$ Evelyn van Weel-Baumgarten, ${ }^{5}$ Chris van Weel ${ }^{5,6}$

To cite: O'Reilly-de Brún $M$, MacFarlane A, de Brún T, et al. Involving migrants in the development of guidelines for communication in crosscultural general practice consultations: a participatory learning and action research project. BMJ Open 2015;5: e007092. doi:10.1136/ bmjopen-2014-007092

- Prepublication history for this paper is available online. To view these files please visit the journal online (http://dx.doi.org/10.1136/ bmjopen-2014-007092).

Received 6 November 2014 Revised 22 March 2015 Accepted 25 March 2015

CrossMark

For numbered affiliations see end of article.

Correspondence to Professor Anne MacFarlane; Anne.macfarlane@ul.ie

\section{ABSTRACT}

Objective: The aim of this research was to involve migrants and other key stakeholders in a participatory dialogue to develop a guideline for enhancing communication in cross-cultural general practice consultations. In this paper, we focus on findings about the use of formal versus informal interpreters because dialogues about these issues emerged as central to the identification of recommendations for best practice.

Design: This qualitative case study involved a Participatory Learning and Action (PLA) research methodology.

Participants: The sample comprised 80 stakeholders: 51 from migrant communities; 15 general practitioners (GPs) and general practice staff; 7 established migrants as peer researchers; 5 formal, trained interpreters; and 2 service planners from the national health authority.

Setting: Galway, Ireland.

Results: There was 100\% consensus across stakeholder groups that while informal interpreters have uses for migrants and general practice staff, they are not considered acceptable as best practice. There was also $100 \%$ consensus that formal interpreters who are trained and working as per a professional code of practice are acceptable as best practice.

Conclusions: Policymakers and service planners need to work in partnership with service providers and migrants to progress the implementation of professional, trained interpreters as a routine way of working in general practice.

\section{INTRODUCTION}

Migration is a global phenomenon and many healthcare systems across the developed world face the challenge of providing culturally competent care. ${ }^{1}{ }^{2}$ Migrants entering a host country often experience language and

\section{Strengths and limitations of this study}

- There is a lack of dialogue between all relevant stakeholders about the relative merits of one type of interpreting over another for communication, for whom and under what conditions.

- This study fills a gap in the literature by describing a participatory dialogue between migrants and other key stakeholders, which was used to generate a guideline for best practice for all stakeholders.

- Findings clarify an important analytic distinction between the usefulness of informal interpreters and their acceptability as best practice, and the need to emphasise the value of trained and professional formal interpreters.

- Migrants and GPS in this study were generating data based on limited experience of formal interpreted consultations and expectations of interpreted consultations with trained professionals-further research is required to explore the evidence base about the impact of high-quality professional interpreting on communication processes and health outcomes for migrants.

cultural barriers when accessing healthcare services. There are formal responses to this communication challenge in practice, such as the use of paid interpreters who may or may not have professional training. There is also a range of informal responses in practice, such as the use of family members, friends, mimes or gestures. ${ }^{3}$

There are policy imperatives to promote the use of formal interpreters, ${ }^{4}$ and research evidence that the use of formal medical interpreting services is the most effective strategy for ensuring accurate 
information exchange in cross-cultural consultations ${ }^{5}$ and that this is a cost-effective strategy. ${ }^{6}$ However, in routine practice in primary care across healthcare jurisdictions the use of formal interpreters is ad hoc and often very low. ${ }^{7} 8$

This translational gap is under-researched, ${ }^{9}$ but the available literature indicates that there are complex challenges related to using formal interpreters in the organisational setting and existing routines of general practice surgeries. ${ }^{7}$ From this literature we know that for general practitioners the using of informal interpreters is often a pragmatic response to these organisational challenges because they are present and 'handy'. Furthermore, while informal interpreters are considered 'second best' from a policy perspective and within the professional interpreting community, some service-users prefer to use family members and friends as interpreters because, in their experience, formal interpreters may align themselves with general practitioners, thus obscuring elements of the patient's narrative. ${ }^{10}$ Therefore, evidence about advantages of formal interpreters for accuracy in interpreting is offset by evidence about advantages of informal interpreters in terms of organisational and interactional gains.

Overall, it appears that there are advantages and disadvantages for different kinds of interpreting for different stakeholders, based on their perspectives: service-user, service provider, policymaker or interpreter. Therefore, it is important to understand more about these shared and differential perspectives in order to develop robust policy and guidelines for practice. However, to date, studies in this field have not explored formal and informal strategies vis-à-vis each other, and these have either generated data with one stakeholder group only ${ }^{8}$ or with a range of stakeholders separately. ${ }^{10}$ This means that there has been no scope for dialogue between stakeholders about the relative merits of one type of strategy over another, for whom and under what conditions.

The motivation for this research is to involve migrants and other key stakeholders in a participatory dialogue about the relative merits of one type of strategy over another to inform the development of a guideline for all stakeholders for enhancing communication in crosscultural general practice consultations. Specific objectives were to:

- Document the range of formal and informal strategies currently in use in general practice consultations;

- Determine the acceptability of different strategies across stakeholder groups;

- Identify, if possible, a shared view about which strategies should be recommended as best practice.

In this paper, we briefly present results about all strategies documented, but focus in particular on findings about the use of formal versus informal interpreters since dialogues about these issues emerged as central to the identification of recommendations for best practice.
METHODS

\section{Design}

The theoretical basis of this research followed the interpretive paradigm and the principles of case study design, ${ }^{11}$ and involved a Participatory Learning and Action (PLA) research methodology ${ }^{12}$ based on the work of Robert Chambers. ${ }^{13}$ PLA is an adaptive strategy that enables diverse groups and individuals to learn, work and act together in a cooperative manner to share, enhance and analyse their knowledge and to plan together for positive action. ${ }^{12} 13$ PLA has been used in primary care research internationally and encourages people to focus on issues that affect them, often enabling positive service-user involvement and empowerment. ${ }^{12} 14$

\section{Study setting}

Ireland has a short history of significant inward migration which started in the late 1990s (see Mac Einri ${ }^{15}$ for an overview of this trend). Latest census shows $12 \%$ of the population are born outside of Ireland (see http:// www.cso.ie/en/census/census2011reports/census2011pro file6migrationanddiversity-aprofileofdiversityinireland). The national health authority-the Health Service Executive (HSE) - published a National Intercultural Health Strategy in 2008 and identified information, language and communication as priority areas for attention. A specific objective was to explore existing formal and informal practices in order to inform the nature and design of a national interpreting service.

This research was designed in partnership with the HSE to progress this objective. The research was conducted in Galway in the west of Ireland between 2009 and 2011. This region had the highest proportion of migrants living in Ireland outside of Dublin, with communities of asylum seekers living in direct provision centres, economic migrants and undocumented migrants. Previous research in the region has shown that there are problems and frustrations for migrants and GPs regarding their consultations together, with a low uptake of formal interpreters and heavy reliance on family and friends as interpreters. ${ }^{3} 1416$ There are commercial interpreting agencies in the region who provide basic training to recruited interpreters but, as is the case elsewhere in Ireland, they do not require interpreters to be professionally trained and accredited. ${ }^{16}$

\section{Sampling and recruitment}

The sample was drawn from five stakeholder groups:

1. Established migrant service-users with capacity to become involved as peer researchers;

2. Migrant service-users with limited English who have experience of accessing and using GP services;

3. GPs and practice staff who work with migrant service-users;

4. Formal trained interpreters;

5. Service planners, social inclusion office, HSE. 
For all stakeholder groups, we followed the principles of purposeful sampling using a combination of network and snowball sampling strategies. ${ }^{17}$ Sampling and recruitment were supported by existing links and key contacts among established migrants, formal trained interpreters, general practice staff and service planners with whom we had connections through previous research and development projects in this field. Sampling for all migrants and general practice stakeholders utilised networks in Galway city, and sampling for formal interpreters and service planners utilised networks in Dublin city.

A key point about sampling and recruitment of' migrants is that we involved established migrants who had the capacity to become involved as peer researchers to work in partnership with the university team to eliminate language, literacy and cultural barriers in the entire research process. The peer researchers were trained in PLA and were known as the Service-User Peer Researchers-'SUPERs'. Through their networks, they facilitated the involvement in the project of a wider group of migrants who spoke limited English, and who had experience of accessing and using GP services in the study region.

\section{Data generation and analysis}

There were three research phases and stakeholders were involved based on the focus of activities in each phase (see table 1).

Data were generated using PLA-style interviews $(n=11)$ and PLA-style focus groups $(\mathrm{n}=25)$. This means that the encounter involved a PLA mode of engagement and the use of PLA techniques to encourage interactive data generation and coanalysis to enhance learning to inform research actions (see below). Interviews were only used when there was a single participant involved/available.

\section{Phase |}

The purpose of phase I was to set the foundation for meaningful involvement of established migrants in a 2 -year research project. The university researchers conducted five PLA-style focus groups with the established migrants over 8 months to (1) develop trust and relationships, integral to PLA partnership, ${ }^{18}$ (2) open the dialogue about communication in cross-cultural general practice consultations by sharing and discussing summaries of key policy and research knowledge prepared by the university researchers and (3) map SUPERs' knowledge of all formal and informal strategies currently in use in daily practice. To complete phase I, the university researchers engaged in 'matched' data-generation (PLA style interviews: $n=4$; PLA style focus groups: $n=2$ ) for literature-sharing and strategy-mapping activities with GPs, practice receptionist, service planners and formal trained interpreters eliciting their perspectives on communication in cross-cultural general practice consultations.

\section{Phase II}

The purpose of phase 2 was to extend the dialogue about commonly used strategies to a broader numbers of stakeholders and to work with stakeholder groups individually to:

- Review the strategies to identify those most specifically related to, and supportive of, cross-cultural general practice consultations, with a focus on the consultation encounter;

Table 1 Overview of stakeholder groups' activities per research phase

\begin{tabular}{|c|c|c|c|}
\hline Stakeholder group & Phase I activities & Phase II activities & Phase III activities \\
\hline $\begin{array}{l}\text { SUPERs: established migrant } \\
\text { service-users }\end{array}$ & $\begin{array}{l}\text { Developed trust } \\
\text { and relationships } \\
\text { with research team } \\
\text { Generated } \\
\text { perspectives on } \\
\text { literature and policy } \\
\text { Mapped commonly } \\
\text { used strategies }\end{array}$ & $\begin{array}{l}\text { Trained as peer researchers } \\
\text { Facilitated fieldwork with wider } \\
\text { group of hard-to-reach migrants } \\
\text { to review phase I mapping to } \\
\text { explore additional strategies, } \\
\text { uses, problems and } \\
\text { acceptability }\end{array}$ & $\begin{array}{l}\text { Dialogue and analysis with } \\
\text { representatives of other } \\
\text { stakeholder groups about phase II } \\
\text { data to identify best practice } \\
\text { strategies for guideline }\end{array}$ \\
\hline $\begin{array}{l}\text { Wider group of 'hard-to-reach' } \\
\text { migrant services users with } \\
\text { limited English and limited } \\
\text { experience of accessing and } \\
\text { using GP services }\end{array}$ & & $\begin{array}{l}\text { Worked with SUPERS to } \\
\text { review phase I mapping to } \\
\text { explore additional strategies, } \\
\text { uses, problems and } \\
\text { acceptability }\end{array}$ & $\begin{array}{l}\text { Reviewed draft recommendations } \\
\text { for best practice strategies for } \\
\text { guideline from completed } \\
\text { interstakeholder dialogue }\end{array}$ \\
\hline $\begin{array}{l}\text { General practice staff } \\
\text { Formal trained interpreters } \\
\text { Service planners }\end{array}$ & $\begin{array}{l}\text { Generated } \\
\text { perspectives on } \\
\text { literature and policy }\end{array}$ & $\begin{array}{l}\text { Reviewed phase I mapping to } \\
\text { explore additional strategies, } \\
\text { uses, problems and } \\
\text { acceptability }\end{array}$ & $\begin{array}{l}\text { Dialogue and analysis with } \\
\text { representatives of other } \\
\text { stakeholder groups about phase II } \\
\text { data to identify best practice } \\
\text { strategies for guideline }\end{array}$ \\
\hline
\end{tabular}


- Explore the perceived usefulness of, and problems associated with, strategies-using a PLA Flexible Brainstorming technique;

- Determine the 'acceptability' of strategies to select those to be considered for inclusion in a guideline of best practice-using a PLA Direct Ranking technique;

- Generate 'ideal scenarios' for cross-cultural consultations, identifying 'new' strategies with potential to improve current practice, also to be considered for inclusion in the guideline-using a PLA Visioning technique.

These PLA techniques are described in international literature about participatory research and are used in international research settings. ${ }^{13}$ In this study, each technique was used to generate, organise and display participants' data, and accompanying individual or focus group interviews were used to explore, synthesise and coanalyse the data. Data were generated on extensive predesigned PLA charts following protocols that ensured that verbal and visual forms of data were recorded in a consistent manner across all stakeholder groups. All PLA charts were computerised after each data generation session in order to preserve the data. Verbal data were recorded on Post-It notes in point form or short phrases rather than in full verbatim quotes. We used researchers' debriefing notes and meeting minutes to augment the data recorded on PLA charts after all data generation sessions. We had permission to audio record data generation sessions with most stakeholder groups throughout the research phases, but migrant participants in phase II elected not to be taped.

The seven SUPERs conducted fieldwork with an extended group of 'hard to reach' migrants, which meant that migrants who could not speak English fluently were included in language-concordant and culturecongruent data generation encounters. There were a total of six focus groups, as two SUPERs from the same community elected to work together. A key feature of the SUPERs' training was to use PLA techniques to 'hear' the voices of the migrant stakeholders and not overpower or alter migrants' perspectives.

As before, the university researchers conducted 'matched' fieldwork with the other stakeholder groups. (PLA style interviews $n=7$; PLA style focus groups $n=9$ )

\section{Phase III}

The purpose of phase III was to have a detailed interstakeholder participatory dialogue about the 'best practice' strategies selected by individual stakeholder groups in phase II and to develop, if possible, a shared view about which strategies should be recommended as best practice for the planned guideline. In phase III, the SUPERs represented themselves and the migrant service-user data in the dialogue with representatives of the general practice; professional, trained interpreters and service planner groups who had participated in phase II.

This interstakeholder group participated in a series of inter-related, iterative, coanalysis PLA-style focus groups $(\mathrm{n}=6)$ to assess phase II data over approximately a 6-month period. We used a PLA Options Assessment technique ${ }^{19}$ to:

- Explore the full range of viable strategies that were deemed in phase II to have high acceptability;

- Record key comments or queries about each strategy;

- Record whether each member of the interstakeholder group considered each viable strategy should be included or not in the guideline;

- Record overall levels of agreement about inclusion of each viable strategy in the planned guideline, for example, 'undecided', included/excluded by democratic majority, included/excluded by consensus.

Not all members of the interstakeholder group could attend all meetings. The computerised data displays created from our PLA Options Assessments enabled us to readily share information at subsequent face-to-face meetings or by email. The university researchers played a major role as 'brokers' during this process to maintain a strong feedback loop between all stakeholders.

All data generated from phases I, II and III were analysed following the principles of thematic analysis ${ }^{20}$ during these iterative cycles of data generation and coanalysis. In addition to coanalysis with the interstakeholder group, the university researchers had regular team meetings and data analysis clinics to discuss and debate emergent issues, and to synthesise key findings. Finally, the university team also had coanalysis meetings with SUPERs to ensure that the SUPERs, as coresearchers, were contributing to the final analysis $(n=3$ PLA-style focus groups).

Findings from our analysis are presented below with a selection of illustrative examples and participant codes. As data were generated in individual and group encounters, some of our participant codes in the results section refer to stakeholder groups and others to individuals.

\section{RESULTS}

Table 2 provides an overview of our sample $(\mathrm{N}=80)$. The SUPERs, migrants and general practice staff were living in Galway city $(n=73)$, and the formal trained interpreters and HSE service planners were Dublin-based $(n=7)$.Many stakeholders participated more than once in the process, depending on their role in the research.

The SUPERs had been living in Ireland for between 6 and 12 years. The profile of the SUPERs in table 3 was drawn from the biographical details provided, and a questionnaire SUPERs codesigned during the early stages of the project.

Prior to their involvement in the project, all seven SUPERs had acted as informal interpreters or advocates for members of their communities. Concerned about such informal practice, they had completed the Northern Ireland Council for Ethnic Minorities (NICEM) interpreters' training course and were interested in improving access to and uptake of formal interpreters in the Republic of Ireland. 
Table 2 Overview of sample per research phase

\begin{tabular}{lllllll}
\hline & $\begin{array}{l}\text { SUPERs } \\
(\mathbf{N}=7)\end{array}$ & $\begin{array}{l}\text { Migrants } \\
(\mathbf{N = 5 1 )}\end{array}$ & $\begin{array}{l}\text { General practice: } \\
\text { GPs+staff }(\mathbf{N = 1 5 )}\end{array}$ & $\begin{array}{l}\text { Formal trained } \\
\text { interpreters (N=5) }\end{array}$ & $\begin{array}{l}\text { HSE service } \\
\text { planners (N=2) }\end{array}$ & $\begin{array}{l}\text { Total } \\
(\mathbf{N}=\mathbf{8 0})\end{array}$ \\
\hline Phase I & 7 & NA & 5 & 1 & 1 & 14 \\
Phase II & 7 & 51 & 5 & 5 & 2 & 70 \\
Phase III & 7 & NA & 10 & 5 & 2 & 24 \\
\hline \multicolumn{7}{l}{ HSE, Health Service Executive; SUPERs, Service-User Peer Researchers. }
\end{tabular}

In terms of the wider sample of migrants $(n=51)$, we could not establish migrants' age-range, gender distribution and other variables with accuracy. This was because many in the sample were in vulnerable circumstances, for example, living as asylum seekers or undocumented migrants and had reasons to be untrusting of 'official' forms and documentation. However, team observations and photographic evidence indicated that there was an evenly balanced male-female distribution and migrants ranged in age from early 20 s to mid-60s. The breakdown of languages spoken was:

- Polish, $\mathrm{n}=8$

- Russian, $\mathrm{n}=9$

- Portuguese, $\mathrm{n}=9$

- French Congolese, $\mathrm{n}=8$

- Urdu, $\mathrm{n}=8$

- Nigerian, $\mathrm{n}=9$

The general practice sample $(n=15)$ comprised Galway-based GPs and practice staff (six males, nine females) with experience of working with refugees, asylum seekers and economic migrants. The formal trained interpreters sample comprised of five females, some of whom were also involved in training and research. The service planners sample comprised two females with senior roles in the HSE Social Inclusion Unit, who had been involved in the development of the Intercultural Health Strategy and were committed to exploring options for interpreting services in Ireland.

\section{Strategies for supporting communication in cross-cultural consultations}

Phase I mapping activities produced a set of 27 strategies commonly used to support communication in crosscultural general practice consultations (see table 4, column 2). During phase II activity, seven of these strategies were selected by stakeholder groups as potential 'best practice' material, to which six distinct strategies were added on to these from 'ideal scenarios' that stakeholders thought could improve current practice. During phase III interstakeholder dialogue, these 13 strategies were grouped into categories of 'communication support'. We identified five core categories of support into which 24 of the 27 strategies mapping in phase I fell: ${ }^{\mathrm{i}}$

\footnotetext{
${ }^{\mathrm{i}}$ The remaining four strategies which fell outside the core categories were carried on into the $\mathrm{SH}$ dialogue, and were dealt with there; for example, $\mathrm{SH}$ agreed that some should be combined or subsumed into core categories, or belonged in special boxes in the guideline text.
}

formal interpreting, bilingual practice staff interpreters, family and friends as interpreters, technologies and visual aids (eg, Google online translation; multilingual posters of body parts), and body language and gestures (see table 4, column 1). These 13 potential 'best practice' strategies (see table 4, column 3) became the focus of interstakeholder dialogue in phase III, and a total of four strategies were ultimately included in the guideline as best practice. Of these, three fell into the category 'formal interpreting' (see table 4, column 4).

In the next section, we elaborate on findings about the use of formal versus informal interpreters because, as previously mentioned, dialogues about interpreting issues were central to the identification of recommendations for best practice. For a summary of findings about the use of body language and gestures, and technology and other visual aids see boxes 1 and 2, respectively.

\section{Analysing usefulness and acceptability of formal and informal interpreting}

Three formal interpreting strategies were identified. Two were in use-formal telephone interpreting; on-site formal face-to-face interpreting. One was considered as a potential ideal scenario-'migrant service-user arranges formal interpreter to accompany her/him to general practice'.

Stakeholders from all groups were very vocal about the uses of formal interpreters. They discussed clinical benefits arising from the competent, effective, accurate, confidential, ethical, neutral and sensitive transmission of messages by a trained interpreter in the consultation (eg, phase II: interpreters, Polish-speaking migrants, SUPERs, Portuguese-speaking migrants, GP\#11, PS\#12, service planners).

Stakeholders discussed interactional benefits for the service-user-GP relationship, that is, the use of a formal interpreter promoted greater trust and satisfaction. The scope for the longer term development of trusting relationships between interpreters and GPs was also mentioned, particularly when there were opportunities to work with each other regularly (phase II: GP\#10, PS\#12, PS\#14, Urdu-speaking migrants, Portuguese-speaking migrants, service planners and interpreters).

In terms of organisational benefits, stakeholders considered that using formal interpreters could save time and money (phase II: Polish and Portuguese-speaking migrants, interpreters). In particular, stakeholders considered that telephone interpreting provided fast access 


\begin{tabular}{|c|c|c|c|c|}
\hline ID code & Gender & Country/region of origin & Languages & Current profession/area of interest/work \\
\hline \#3 & Female & Russia & $\begin{array}{l}\text { Russian } \\
\text { English }\end{array}$ & $\begin{array}{l}\text { Migrant support and advocacy worker } \\
\text { Community interpreter }\end{array}$ \\
\hline \#4 & Female & Nigeria & $\begin{array}{l}\text { Ebo/Yoruba/Hausa } \\
\text { English }\end{array}$ & $\begin{array}{l}\text { Social worker } \\
\text { Community interpreter }\end{array}$ \\
\hline \#5 & Female & Poland & $\begin{array}{l}\text { Polish } \\
\text { English }\end{array}$ & $\begin{array}{l}\text { Health care assistant } \\
\text { Community interpreter }\end{array}$ \\
\hline \#6 & Male & Pakistan & $\begin{array}{l}\text { Urdu } \\
\text { English }\end{array}$ & $\begin{array}{l}\text { IT technician } \\
\text { Community interpreter }\end{array}$ \\
\hline \#7 & Male & Democratic Republic of the Congo & $\begin{array}{l}\text { French } \\
\text { Lingala } \\
\text { English }\end{array}$ & $\begin{array}{l}\text { Student } \\
\text { Community interpreter }\end{array}$ \\
\hline \#8 & Female & Portugal & $\begin{array}{l}\text { Portuguese } \\
\text { English } \\
\text { Spanish } \\
\text { French }\end{array}$ & $\begin{array}{l}\text { Interpreter and translator } \\
\text { LLM student (Public Law) } \\
\text { Community interpreter }\end{array}$ \\
\hline \#9 & Female & Nigeria & $\begin{array}{l}\text { Igbo/Yoruba/Hausa } \\
\text { English }\end{array}$ & $\begin{array}{l}\text { IT support engineer } \\
\text { Community interpreter }\end{array}$ \\
\hline
\end{tabular}

to interpreting for both the GP and the service user (phase II: Russian-speaking migrants, interpreters; phase III: interstakeholder working group).

Stakeholders did record problems with the use of formal interpreters; for example, the Polish-speaking migrants (phase II) recorded that there can be a lack of intimacy because of having a third person in the consulting room and that they can feel discomfort if the interpreter is of a different sex. GPs remarked that a third party intrudes on the usual doctor-patient dynamic (GP\#10). Interpreters who do not follow professional codes of ethics can have prejudices that impact negatively on the consultation (phase II: formal interpreters). Finally, the practicalities of arranging for service user, interpreter and GP to meet at the same time in the one location are challenging (phase II: formal interpreters, GP\#11).

However, on balance, stakeholders were more favourable than critical about this strategy. This became very apparent during phase II Direct Ranking activity, in which each individual stakeholder group ranked all strategies about formal interpreting very highly and deemed these to have high acceptability as best practice (see table 4, column 3).

Four informal interpreting strategies were identified: service-user using a child, adult family member or friend as interpreter in face-to-face consultations and service-user arranging to have own informal interpreter available over a mobile phone.

All stakeholder groups, apart from the formal, trained interpreters, considered that informal interpreters had certain uses. For example, they were considered 'handy' because they lived nearby (phase II: Urdu-speaking group) and could provide a measure of enhanced understanding in consultations (phase II: Russian-speaking group, Portuguese-speaking group, GP\#10, GP\#11); and as a service-user's trusted choice, they provided support in the GP-service-user relationship dynamics (GP\#13 and PS\#12). Also, it was sometimes comforting and supportive to have a family member or friend interpreting and acting as an advocate and mentor, knowledgeable about both native and host cultures (phase II: French-Congolese-speaking migrants; Urdu-speaking migrants, service planners, GP\#10, PS\#12).

Table 4 Categories of support for communication in cross-cultural consultations per research phase

\begin{tabular}{|c|c|c|c|}
\hline Category of support & $\begin{array}{l}\text { Strategies mapped in } \\
\text { phase I }(n=27) \\
\text { Relevant to core } \\
\text { categories }(n=23)\end{array}$ & $\begin{array}{l}\text { Top-ranked strategies (from phase I) } \\
\text { plus 'new' additions (from phase II) } \\
\text { identified for consideration as 'best } \\
\text { practice' ( } n=13)\end{array}$ & $\begin{array}{l}\text { Strategies identified } \\
\text { as best practice in } \\
\text { phase III }(n=4)\end{array}$ \\
\hline Formal interpreting & 3 & $3+2$ new & 3 \\
\hline $\begin{array}{l}\text { Bilingual practice staff as } \\
\text { interpreters }\end{array}$ & 2 & $2+2$ new & 1 \\
\hline $\begin{array}{l}\text { Family and friends as } \\
\text { interpreters }\end{array}$ & 4 & 0 & 0 \\
\hline Technologies and visual aids & 11 & $1+2$ new & 0 \\
\hline Body language and gestures & 3 & 1 & 0 \\
\hline
\end{tabular}


Box 1 Examples of problems with body language and gestures

- Body language is an everyday communication tool the GP may use to signal friendliness/comfort to a service-user (GP\#10, PS\#12, GP\#13, GP\#11, Nigerian migrants, PS\#14) but is unreliable as a diagnostic support (Polish migrants; GP\#10, GP\#13, GP\#11, Russian migrants, PS\#12, PS\#14, Urdu-speaking migrants)

- Different cultural backgrounds can lead to misunderstanding of body language (GP\#10, GP\#13, PS\#14, Polish migrants)

- Imprecise, incomplete form of communication (GP\#11, Polish migrants, PS\#12, PS\#14, formal interpreters)-very difficult to explain how to take medication using body language/ gesture (PS\#12)

- Stressful for all involved (Polish migrants, PS\#12, PS\#14)

- Frustrating/unhelpful for GP who wants service-user to get the best help possible (GP\#11, GP\#13-DR; PS\#12)

However, all stakeholder groups agreed that there are serious problems with informal interpreters. They discussed the intertwined problems of lack of training and lack of competency (phase II: service planners, Urdu-speaking migrants, PS\#12). Family or friends who act as interpreters do not necessarily have fluency in English (PS\#12, PS\#14), and cannot always be available for GP appointments because of their own family or work commitments (phase II: Urdu-speaking group). Migrants also presented a counterpoint to 'comfort and advocacy', suggesting that this could lead to a lack of privacy for the presenting patient (phase II: French-Congolese-speaking migrants, Russian-speaking migrants, Portuguese-speaking migrants); concerns were also raised about informal interpreters pushing their own agendas (GP\#10, GP\#13) and abusive spouses accompanying service-users to act as informal interpreters (GP\#13, service planners, PS\#14).

All stakeholders had additional and strong views about problems associated with using children as interpreters (see box 3). The impact of missing school in order to interpret, potential for trauma and embarrassment, for example, were considered highly problematic. When ranking these strategies in terms of acceptability, the consensus across stakeholder groups was that their acceptability as best practice was low (see table 4, column 4 and table 5, column 4).

\section{Interstakeholder dialogue to identify strategies for inclusion in the guideline}

At the start of phase III, the interstakeholder group reviewed phase II data about informal interpreters. They endorsed the findings, and none of the four strategies about informal interpreting were included as best practice in the guideline.

Focusing on findings from Phase II about formal interpreting, there was $100 \%$ consensus among the interstakeholder group that the use of formal interpreting
Box 2 Examples of problems with technological and visual aids

- When desperate people are under stress, it may be helpful, but a computer programme is a tool, not an ideal for best practice (SUPERS, GP\#11)

- Computer programs are cold, interruptive of the intimacy of the consultation, and can be intimidating (SUPERs)

- Computer programs are open to misinterpretation (Russian migrants)

- Visual aids are perhaps useful as a basic explanatory tool or as a complementary tool alongside the use of a professional interpreter, but not best practice (service planners, GP\#13, Interpreters, Portuguese migrants)

- Bilingual or multilingual materials cannot cope with psychological/mental health/social health issues (GP\#11)

- Bilingual or multilingual materials are not three-dimensional, so have limited use (GP\#10, service planners, Polish migrants)

- Service-user's language may not be included in the material being used (Nigerian migrants)

should be included in the guideline as best practice. However, there were long deliberations about how these data should be presented in the guideline with attention focused on emphasising the importance of training for interpreters, specific conditions that are required for high-quality professionalism among formal interpreters and implementation challenges.

Through this dialogue, stakeholders with experience of training interpreters shared their expertise with other stakeholders, focusing on specific recommendations which related to the requirements for high-quality formal, trained, professional interpreting (see box 4).

From this dialogue, all stakeholders agreed that formal, trained professional, face-to-face and telephone interpreting should be included in the planned

Box 3 Examples of problems with using children as interpreters

- A child is not a professional interpreter and is unlikely to have a medical vocabulary (Polish-speaking, Russian-speaking and Urdu-speaking migrants)

- A child may have limited English; important information could be missed (GP\#11, PS\#12, Nigerian migrants)

- A child may not be available (during school hours) or may be missing out on schooling (Russian migrants, service planners, Urdu-speaking migrants)

- The authority of parents may be compromised by a reliance on their child to interpret (GP\#11)

- A child may be traumatised (Russian migrants), embarrassed, frightened or confused; does not have sufficient 'emotional distance' (Congolese and Portuguese migrants, GP\#11)

- There may be fear or shame on the part of the parent and/or child - both may be embarrassed (Polish migrants, GP\#10, GP\#13) 


\begin{tabular}{|c|c|c|c|}
\hline $\begin{array}{l}\text { Type of } \\
\text { interpreting }\end{array}$ & $\begin{array}{l}\text { Strategies identified during mapping: } \\
\text { phase I and phase II }\end{array}$ & $\begin{array}{l}\text { Data on usefulness from } \\
\text { direct ranking: phase II }\end{array}$ & $\begin{array}{l}\text { Acceptability rating from } \\
\text { direct ranking: phase II }\end{array}$ \\
\hline \multirow[t]{3}{*}{ Formal interpreting } & Formal telephone interpreting & Yes & High \\
\hline & On-site formal face-to-face interpreting & Yes & High \\
\hline & $\begin{array}{l}\text { Service-user arranges formal face-to-face } \\
\text { interpreter to accompany her/him to GP } \\
\text { surgery }\end{array}$ & Yes & High \\
\hline \multirow[t]{4}{*}{$\begin{array}{l}\text { Family and friends } \\
\text { as interpreters }\end{array}$} & $\begin{array}{l}\text { Service-user uses child as face-to-face } \\
\text { interpreter }\end{array}$ & Yes & Low \\
\hline & $\begin{array}{l}\text { Service-user uses adult family member as } \\
\text { face-to-face interpreter }\end{array}$ & Yes & Low \\
\hline & $\begin{array}{l}\text { Service-user uses a friend as face-to-face } \\
\text { interpreter }\end{array}$ & Yes & Low \\
\hline & $\begin{array}{l}\text { Service user arranges to have own 'informal' } \\
\text { interpreter on mobile phone }\end{array}$ & & \\
\hline
\end{tabular}

guideline, and that details about the context and specificity of their use should also be included.

The ideal scenario strategy-'service-user arranges own formal face-to-face interpreter'-was discussed at great length, with consideration given to the potential empowerment of service users by organising their own interpreter versus the burden it might place on them and the levels of health literacy required to do so. Overall, stakeholders concluded that a better supply of high-quality trained interpreters would need to be available in the system before this strategy could be effectively progressed. Therefore, at the end of their dialogue, the stakeholders agreed not to include this as a form of best practice at this time. Therefore, only two 'best practice' strategies from this category were included in the guideline (table 4, column 4).

Finally, strategies about the use of bilingual practice staff were all ruled out apart from the idea of service-users consulting with a GP who was completely bilingual and able to converse fluently in a medical consultation in the same language as the service user.

At the end of phase III, over two-thirds of the migrants who had participated in phase II returned to the

Box 4 Key recommendations from experts in training of interpreters and professionalising interpreting practice

\section{Professionalising interpreting}

- Interpreters should be formal, trained, qualified, accredited professionals, ideally well versed in medical interpreting

- Interpreter is ethically responsible and abides by a recognised relevant Code of Ethics

- Interpreter ought to possess necessary skills to coordinate the interaction (whether face-to-face or by telephone)

- Interpreter ought to be monitored for professional conduct and best practice

- Every consultation should be regarded as a potentially serious medical condition as the nature of the medical condition or seriousness of the condition cannot and should not be established by the GP or anyone else a priori university to view a draft guideline. Working in small groups with their language-concordant SUPER, they assessed information about the phase III dialogue, with a focus on key deliberations, learnings and decisions. The proposed draft guideline was endorsed by all and the content was subsequently considered final.

\section{DISCUSSION}

\section{Summary of findings}

Migrants and other key stakeholders agreed that a combination of strategies was highly acceptable for inclusion as best practice in a national guideline on communication in cross-cultural consultations. The common feature among these strategies was that these related to the use of formal, trained professionals: professional interpreters for telephone and face-to-face interpreting, and bilingual GPs who are completely fluent in the language of the service-user with whom they are consulting. Strategies with low acceptability across stakeholder groups, which were not included in the guideline, related to the use of family members and friends as interpreters and other informal strategies such as the use of dictionaries or technological and visual aids. These findings are based on democratic PLA dialogues within and across stakeholder groups and reveal important differences between the usefulness and acceptability of strategies in practice. The consensus across stakeholder groups, after their dialogues, was striking.

\section{Methodological critique}

The use of a PLA methodology and a series of interactive data generation techniques are novel in the field of academic primary care. This is a major strength in this research and is in accordance with ethical guidance for research with black and minority ethnic (BME) communities. $^{21} 22$ The use of PLA techniques had a consistent and positive impact on the dynamics during data generation, particularly during PLA-style focus groups interviews as participants were comfortable, and 
engaged with each other and the researchers The research was led by experienced PLA researchers and included significant capacity-building for established migrant participants, that is, training of SUPERs to act as peer researchers and productive efforts to meaningfully engage a relevant sample of hard-to-reach migrants and other stakeholders.

In terms of representativeness, and following qualitative understandings of representation, we consider that, overall, this was a sample with a range of sociodemographic backgrounds and a valuable range of diversity in terms of stakeholders' expertise about the issue under investigation. For example, the sample of migrants comprised those who were well established in Ireland with considerable security (ie, the seven SUPERs) and others who had newly-arrived and were living in vulnerable circumstances, for example, in direct provision centres or as undocumented migrants (ie, the wider group of 51 migrants). Also, there was a range of English language abilities and of people who had experience of using informal and formal interpreters, and of acting as informal and formal interpreters. The GP community was represented by staff from different practices with a relatively high volume of migrants and who were, most typically, using informal interpreters in their daily practice. The health service planners had responsibility for developing HSE systems to improve communication with an open mind about what that system should be.

We acknowledge that the SUPERs had a strong commitment to developing formal interpreting services in Ireland. We have to consider whether this had an undue influence on phase II data generation. However, it is important to reiterate that their training was to use PLA techniques to 'hear' the voices of the migrant SHs and not to overpower or alter migrants' perspectives. Furthermore, key decisions about the low acceptability of informal interpreters were made by stakeholders from the wider migrant population and general practice settings and the HSE, working separately in their individual groups during phase II.

Certainly the interest of SUPERs and formal trained interpreters in formal interpreting would have influenced the interstakeholder PLA dialogue about strategies for inclusion in the guideline in phase III. However, this was precisely the point of the PLA dialogue: for stakeholders to share and learn from each other's perspectives and work together to see if it were possible to develop shared views about best practice. After hearing each other's perspectives, each member of the interstakeholder group had the chance to express an individual opinion as to whether a strategy should be included or not. This was the reason for recording whether final decisions about the content of the guideline during phase III were arrived at by minority, majority or consensus view.

Overall, while dialogue cannot in and of itself change the status quo in practice, the PLA dialogue was an important advance in this process of guideline development. We noted several 'Aha moments' during which stakeholders noted and acknowledged the ways in which they had gained enhanced learning by listening to each other's perspectives; this led stakeholders to 'shift position' and alter their original perspectives.

PLA is a resource-intensive process and requires both meticulous planning to ensure quality and responsiveness to the organic and iterative research process. In this project, it was particularly intensive to design effective training and capacity-building for the established migrants to work as peer researchers in their own communities. However, this is equally the strength of the research because the PLA approach enhanced recruitment of hard-to-reach migrants and eliminated language and cultural barriers from the fieldwork, which enabled meaningful participation. Therefore, the investment of resources had instrumental, practical and ethical gains.

The resultant data fill a gap in the literature by providing a democratically developed guideline for best practice that is based on a composite of learning experiences across a robust sample without comprising the individual 'voice' of any one stakeholder group. Guidelines arrived at in this participatory way are rare and increase the implementability of guidelines into practice. $^{23} 24$

\section{Findings discussed in relation to the literature}

The findings from this study provide significant details about a wide range of strategies commonly used to manage communication in cross-cultural general practice consultations, confirming previous analysis about this translational gap ${ }^{25}$ and adding more detail about the variety of informal interpreting strategies.

These findings support previous research about problems with informal interpreting, including the issue of error, ${ }^{5}$ and the complex social difficulties that can arise from informal interpreting arrangements such as the specific problems of using children ${ }^{26}$ and the burden of work on migrants to find informal interpreters whom they know and trust. ${ }^{14}$

Findings from this study also support previous research which indicates that service-users sometimes benefit from having a family member or friend present as an interpreter during a cross-cultural consultation. ${ }^{10} 27$ Also, there is an argument for case-by-case analysis of what is 'good' for each individual consultation so that preferences for using family members or friends can be taken into account. ${ }^{27}$ However, we argue that the analytic emphasis in this research is on acceptability rather than usefulness, and the use of a participatory dialogue to exchange perspectives across stakeholder groups is key to this research. This stimulated thoughtful discussion and debate during phase III about whether it was appropriate to put strategies involving informal interpreters into a national guideline for best practice. Thus, while stakeholders in phase II acknowledged when and why other strategies may be employed, and understood the very complex 
organisational challenges involved in implementing the use of formal interpreters in routine practice, the result of their dialogue was a clear consensus that informal interpreting should not be promoted as best practice for the guideline under development.

In acknowledgement of these complexities, we propose two specific areas for further research. First, a comprehensive analysis of the implementation of formal interpreting in general practice and primary care settings. Participants in this study emphasised that issues of training interpreters, monitoring professional practice, financial compensation for interpreters and the challenges of organising bookings for interpreted consultations may act as levers or barriers to implementation of existing guidelines. Other research highlights that the match between service-users and interpreters in terms of origin, religion, dialect, gender and political views will affect the implementation ${ }^{28}$ and that the dynamics of trust in cross-cultural consultations need careful consideration. ${ }^{29}$ However, apart from some exceptions ${ }^{9} 163031$ there is a lack of research in this area and this should be addressed. Second, it would be valuable to conduct further research to explore the dynamics of a four-way consultation in which a service user's family member is present for emotional support and whether/how it impacts on the quality of the formal interpreter's role.

Finally, it is important to note that participants in Greenhalgh et al $\mathrm{s}^{10}$ study had direct experience of both kinds of interpreting and from this, they reported problems with formal interpreters. In contrast, migrants and GPs in this study were generating data based on limited experience of formal interpreted consultations and expectations of interpreted consultations with trained professionals. However, some of the problems noted in Greenhalgh et $a l \mathrm{~s}^{10}$ work are, from some stakeholders' perspectives, poor professional practice. It is not wise to undermine the value of formal interpreting on the basis of (perceived) poor practice. Like Greenhalgh et al, we argue that it is important to clarify the appropriate working role of interpreters and to concentrate on improving training, monitoring and evaluation so that all stakeholders are experiencing quality formal interpreting. We would not, for example, question the value of practice nurses or GPs as a healthcare provider because of poor practice, but would work to support best practice through nursing and medical organisations. We need to research a cohort of migrants, GPs and professional trained interpreters who are working to the highest professional standards to add to the evidence base about the impact of professional interpreting on communication processes and health outcomes for migrants.

\section{CONCLUSION}

In keeping with previous research, these findings from a participatory and interstakeholder research project indicate that family and friends are used as informal interpreters in general practice, and that they are sometimes useful in that role. However, we conclude that they are not acceptable as best practice. Policymakers and service planners need to work in partnership with service providers and migrants to progress the implementation of professional, trained interpreters as a routine way of working in general practice.

Author affiliations

${ }^{1}$ National University of Ireland, Galway, Ireland

${ }^{2}$ University of Limerick, Limerick, Ireland

${ }^{3}$ Galway Migrant Service, Galway, Ireland

${ }^{4}$ Portuguese Association of Ireland, Galway, Ireland

${ }^{5}$ Radboud University Nijmegen Medical Centre, Radboud University, the Netherlands

${ }^{6}$ Australian National University, Australian Primary Health Care Research Institute, Canberra, Australia

Acknowledgements The authors thank colleagues in the Health Service Executive Social Inclusion Unit for collaborating on the study design and conduct. The authors also thank all participants who contributed generously to the research process.

Contributors $\mathrm{MOdB}, \mathrm{AM}$, and $\mathrm{TdeB}$ have made substantial contributions to the conception, design of the work. MOdB and AM contributed to the drafting of the work and all other authors revised it critically for important intellectual content. All authors have made substantial contributions to the acquisition, analysis, or interpretation of data for the work. All authors have given approva for the final version to be published and agree to be accountable for all aspects of the work by ensuring that questions related to the accuracy or integrity of any part of the work are appropriately investigated and resolved.

Funding This research was funded by the Health Research Board Partnership Award 2009-2011, and supported by funding from the European Union Seventh Framework Programme (FP7/2007-2013) under Grant Agreement No 257258.

Competing interests $\mathrm{MOdB}$ and $\mathrm{TdeB}$ are $\mathrm{Co}$-Founders and Co-Directors of the Centre for Participatory Strategies-research and training organisation for Participatory Learning and Action research.

Ethics approval Irish College of General Practitioners, Dublin.

Provenance and peer review Not commissioned; externally peer reviewed.

Data sharing statement No additional data are available.

Open Access This is an Open Access article distributed in accordance with the Creative Commons Attribution Non Commercial (CC BY-NC 4.0) license, which permits others to distribute, remix, adapt, build upon this work noncommercially, and license their derivative works on different terms, provided the original work is properly cited and the use is non-commercial. See: http:// creativecommons.org/licenses/by-nc/4.0/

\section{REFERENCES}

1. USDHSS. National standards for cultural and linguistically appropriate services in health care final report. Washington DC: Health UDoHaHSOoM, 2001

2. Betancourt J, Green A, Carrillo J, et al. Defining cultural competence: a practical framework for addressing racial/ethnic disparities in health and health care. Public Health Rep 2003;118:293-302.

3. MacFarlane A, Glynn LG, Mosinkie PI, et al. Responses to language barriers in consultations with refugees and asylum seekers: a telephone survey of Irish general practitioners. BMC Fam Pract 2008;9:68

4. Council of Europe. Protocol No. 12 to the convention for the protection of human rights and fundamental freedoms. Strasbourg: Council of Europe, 2000.

5. Flores $\mathrm{G}$. The impact of medical interpreter services on the quality of health care: a systematic review. Med Care Res Rev 2005;62:255-99. 
6. Bischoff A, Denhaerynck K. What do language barriers cost? An exploratory study among asylum seekers in Switzerland. BMC Health Serv Res 2010;10:248.

7. Greenhalgh T, Voisey C, Robb N. Interpreted consultations as 'business as usual'? An analysis of organisational routines in general practices. Sociol Health III 2007;29:931-54.

8. Priebe S, Sandhu S, Dias S, et al. Good practice in health care for migrants: views and experiences of care professionals in 16 European countries. BMC Public Health 2011:11:187-98.

9. van den Muijsenbergh $\mathrm{M}$, van Weel-Baumgarten $\mathrm{E}$, Burns $\mathrm{N}$, et al. Communication in cross-cultural consultations in primary care in Europe: the case for improvement. The rationale for the RESTORE FP 7 project. Primary Health Care Res Dev 2013;15:122-33.

10. Greenhalgh T, Robb N, Scambler G. Communicative and strategic action in interpreted consultations in primary health care: a Habermasian perspective. Soc Sci Med 2006;63:1170-87.

11. Stake RE. The art of case study research. Thousand Oaks, CA: Sage, 1995.

12. O' Reilly-de Brún M, de Brún T. The use of Participatory Learning \& Action (PLA) research in intercultural health: some examples and some questions. Translocations: Migration Soc Change 2010;6. http://www.translocations.ie/v06i01.html

13. Chambers R. Whose reality counts? Putting the first last. London: Intermediate Technologies Publications, 1997.

14. MacFarlane A, Dzebisova Z, Karapish D, et al. Arranging and negotiating the use of informal interpreters in general practice consultations: experiences of refugees and asylum seekers in the west of Ireland. Soc Sci Med 2009;69:210-14.

15. Mac Einri P. Integration models and choices. In: Fanning B, ed. Immigration and social change in the republic of Ireland. Manchester: Manchester University Press, 2007:214-36.

16. MacFarlane A, O'Reilly-de Brún M. An evaluation of uptake and experience of a pilot interpreting service in general practice in the HSE Eastern Region. Galway: National University of Ireland Galway, 2009.

17. Patton M. Qualitative evaluation and research methods. London: Sage, 1990

18. Cornwall A, Jewkes R. What is participatory research? Soc Sci Med 1995;41:1667-76.

19. O'Kane E, O'Reilly-de Brún M. Doing your own research. London: Marion Boyars, 2001.
20. Silverman D. Theory and method in qualitative research. In: Silverman $\mathrm{D}$, ed. Interpreting qualitative data: methods for analysing talk, text and interaction. Trowbridge, UK: Cromwell Press, 1993:1-29.

21. Feldman A, Frese C, Yousif T. Research development and critical interculturalism: a study on the participation of refugees and asylum seekers in research and development based initiatives. Dublin: Social Science Research Centre, University College Dublin, 2002.

22. Johnson MD. Engaging communities and users: health and social care research with ethnic minority communities. In: Nazaroo JY, ed. Health and social research in multiethnic societies. London Routledge, 2006:48-64.

23. Chowdhury AN, Banerjee S, Brahma A, et al. Participatory research for preventing pesticide-related DSH and suicide in Sundarban, India: a brief report. ISRN Psychiatry 2013;2013:427417.

24. Greenhalgh T, Robert G, Macfarlane F, et al. Diffusion of innovations in service organizations: systematic review and recommendations. Milbank Q 2004;82:581-629.

25. MacFarlane A, Singleton C, Green E. Language barriers in health and social care consultations in the community: a comparative study of responses in Ireland and England. Health Policy 2009;92:203-10.

26. Cohen S, Moran-Ellis J, Smaje C. Children as informal interpreters in GP consultations: pragmatics and ideology. Sociol Health III 1999;21:163-86.

27. Hadziabdic E, Albin B, Heikkilä K, et al. Family members' experiences of the use of interpreters in health care. Prim Health Care Res Dev 2014;15:156-69.

28. Hadziabdic E, Hjelm K. Arabic-speaking migrants' experiences of the use of interpreters in healthcare: a qualitative explorative study. Int J Equity Health 2014;13:49.

29. Dahal G, Qayyum A, Ferreya M, et al. Immigrant community leaders identify four dimensions of trust for culturally appropriate diabetes education and care. J Immigr Minor Health 2014;6:978-84

30. MacFarlane A, O'Donnell C, Mair F, et al. REsearch into implementation STrategies to support patients of different ORigins and language background in a variety of European primary care settings (RESTORE): study protocol. Implement Sci 2012;20:111.

31. Hadziabdic E, Heikkilä K, Albin B, et al. Problems and consequences in the use of professional interpreters : qualitative analysis of incidents from primary healthcare. Nurs Inq 2011;18:253-61. 